\title{
Functionalised Clathrochelate Complexes - New Building Blocks for Supramolecular Structures
}

\author{
Matthew D. Wise $\S^{\star}$ and Kay Severin \\ §SCS-Metrohm Award for best oral presentation
}

\begin{abstract}
Tris(dioxime) iron(II) clathrochelate complexes functionalised with 3- and 4-pyridyl groups have been employed as building blocks in the preparation of supramolecular structures by coordination-driven self-assembly. These complexes possess a number of desirable characteristics, being straightforward to synthesise and offering ample opportunity for steric and functional modification. Clathrochelate-based 4,4'-bipyridyl metalloligands from $1.5 \mathrm{~nm}$ to $5.4 \mathrm{~nm}$ in length were prepared in up to two steps and their potential as building blocks for supramolecular architectures demonstrated through the preparation of a discrete molecular square and a three dimensional (3D) coordination polymer. Furthermore, the structure-directing capability of clathrochelate building blocks was illustrated through the synthesis of octahedral cage compounds, which are capable of encapsulating the large, hydrophobic $\mathrm{BPh}_{4}{ }^{-}$anion in aqueous solvent mixtures.
\end{abstract}

Keywords: Clathrochelate complexes, Metalloligands, Palladium, Self-assembly

Coordination-driven self-assembly has emerged as an extremely powerful tool in the preparation of discrete and polymeric supramolecular structures. ${ }^{[1]}$ This approach entails combining two types of building block - an acceptor, which contains one or more metals with at least one vacant coordination site, and a donor, which contains multiple Lewis basic functional groups - via reversible coordinate bonds. Ultimately, the dimensionality, structure and function of self-assembled architectures are determined by their component building blocks and, consequently, the design and preparation of new building blocks is an important aspect of supramolecular chemistry. The synthesis and structural elaboration of linear 4,4'-bipyridyl ligands in particular have received much attention, given their ubiquity in coordina-

\footnotetext{
${ }^{\star}$ Correspondence: M. D. Wise

Institut des Sciences et Ingénierie Chimiques Ecole Polytechnique Fédérale de Lausanne (EPFL) $\mathrm{CH}-1015$ Lausanne
}

E-mail: matthew.wise@epfl.ch tion-driven self-assembly as linking struts between two metal acceptor units. ${ }^{[1]}$ The closely structurally related 3,3'-bipyridyl ligand has, in contrast, remained relatively scarcely exploited as a supramolecular building block, given its inherent structural variability. ${ }^{[1,2]}$

Herein, we demonstrate that $\mathrm{Fe}(\mathrm{II})$ tris(dioxime) clathrochelate complexes ${ }^{[3]}$ capped with boronic acids are attractive scaffolds for the preparation of both 3,3'and 4,4'-bipyridyl metalloligands. These complexes, which have been known for many years and extensively investigated, ${ }^{[4]}$ are comprised of an $\mathrm{Fe}(\mathrm{II})$ ion encapsulated within a tris(dioxime) macrobicyclic ligand bearing a 2- charge, and are electrostatically neutral and diamagnetic. Tris(dioxime) $\mathrm{Fe}(\mathrm{II})$ clathrochelates are also sufficiently stable to be handled and stored under ambient conditions and purified by chromatography on silica gel. Furthermore, metalloligands based upon clathrochelate complexes are rigid, linear and offer two opportunities for structural and functional modification - through the oxime substituents and boronic acid capping group.

Tris(dioxime) clathrochelate complexes functionalised with 3- and 4-pyridyl groups were prepared from $\mathrm{FeCl}_{2}$, a 1,2-dioxime (2,3-butanedione dioxime (dimethylglyoxime) or 1,2-cyclohexanedione dioxime (nioxime)), and either pyridin-3yl or pyridin-4-yl boronic acid in good yields (Scheme 1). ${ }^{[5]}$ These starting materials are all commercially available.
Having prepared these simple clathrochelate complexes, we began to explore the possibility of preparing longer 4,4'-bipyridyl metalloligands through homologation of the $\mathrm{Fe}$ (II) tris(dioxime) complex cores. Two strategies were developed in order to achieve this (Scheme 2), both of which require the addition of a second boronic acid to the reaction mixture. Introduction of 1,4-benzenediboronic acid or 4,4'-biphenyldiboronic acid led to the formation of bis(clathrochelate) complexes 5 and 6 in a one-pothomologation approach. The yields of these compounds are $31 \%$ and $27 \%$ respectively, the major side product in each case being 2 . The second strategy entailed the addition of either 4-iodobenzeneboronic acid or 4-alkynylbenzeneboronic acid to the reaction mixture. These starting materials, in combination with di(n-octyl)glyoxime and $\mathrm{FeCl}_{2}$, led to the formation of $\mathbf{7}$ and $\mathbf{8}$, in addition to the symmetric clathrochelate complexes functionalised with 4-pyridyl, 4-alkynyl or 4-iodo groups exclusively.

Alkynyl- and iodo-functionalised boronic acids were employed in the synthesis of $\mathbf{7}$ and $\mathbf{8}$ since these functional groups may be connected using a standard Sonogashira cross coupling approach. ${ }^{[6]}$ This technique enabled the rod-shaped, 4-pyridyl-functionalised homologated bis(clathrochelate) complexes 9-11 to be prepared (Scheme 3). Metalloligand 9 was prepared through the direct coupling of 7 and $\mathbf{8}$, metalloligand $\mathbf{1 0}$ by coupling two molecules of $\mathbf{8}$ with 1,4-diiodobenzene 

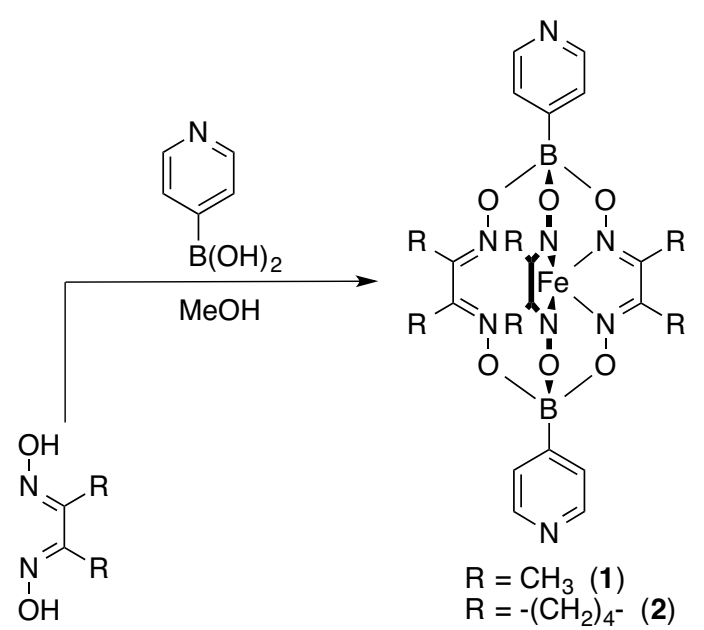

$\mathrm{R}=\mathrm{CH}_{3}$ (1)

$\mathrm{R}=-\left(\mathrm{CH}_{2}\right)_{4^{-}}(\mathbf{2})$
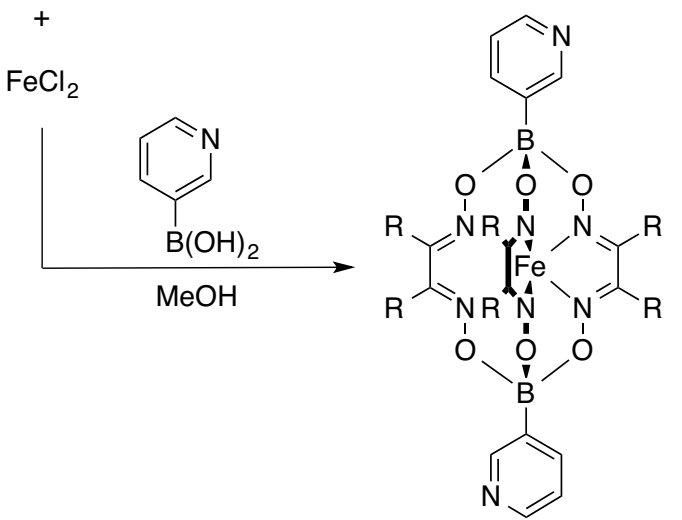

$\mathrm{R}=\mathrm{CH}_{3}$ (3)

$\mathrm{R}=-\left(\mathrm{CH}_{2}\right)_{4}^{-}$(4)

Scheme 1. Synthesis of 3,3'- and 4,4'-bipyridyl clathrochelate based metalloligands 1-4.

(B), and metalloligand $\mathbf{1 1}$ by coupling two molecules of $\mathbf{8}$ with a symmetrical clathrochelate complex functionalised with 4-iodo groups at each end (A).

The structures of $\mathbf{2}$ and $\mathbf{5}$ were unambiguously confirmed by single crystal X-ray crystallography (Fig. 1) and their internal $\mathrm{N} \cdots \mathrm{N}$ distances revealed to be $1.5 \mathrm{~nm}$ and $2.7 \mathrm{~nm}$ respectively. Additionally, a molecular modelling approach was developed to predict the lengths of $\mathbf{6}$ and 9-11, which combined molecular dynamics with the single crystal structure data of $\mathbf{2}$ and $\mathbf{5}$. This technique confirmed the $\mathrm{N} \cdots \mathrm{N}$ distance in 11 to be $5.4 \mathrm{~nm}$. The fact that a building block of this length can be prepared from simple starting materials in two steps illustrates the benefits that clathrochelate complexes offer in terms of both their size and the extent to which they may be functionally modified through the boronic acid capping group. By means of comparison, Stoddart, Yaghi and coworkers reported the synthesis of an oligophenyl building block with terminal hydroxycarboxylic acid groups $5.0 \mathrm{~nm}$ in length, which was prepared by an 11-step synthesis. ${ }^{[7]}$

Scheme 2. Synthesis of the clathrochelate complexes 5-8.
In order to demonstrate the potential of 4,4'-bipyridyl clathrochelate metalloligands as building blocks for coordination-driven self-assembly, we incorporated 2 into representative 2D and 3D supramolecular architectures. A 2D molecular square (12) was synthesised by heating a 1:1 mixture of 2 and $f a c$ - $\mathrm{Re}(\mathrm{CO})_{3}\left(\mathrm{CH}_{3} \mathrm{CN}\right)_{2} \mathrm{Cl}$ in chloroform. This heterometallic assembly was unambiguously characterized by single crystal X-ray analysis (Fig. 2). In addition to this discrete architecture, we prepared a mixed-ligand 3D coordination polymer. Heating a solution of $\mathrm{Zn}\left(\mathrm{NO}_{3}\right)_{2} \cdot 6 \mathrm{H}_{2} \mathrm{O}, 4,4$ '-biphenyldicarboxylic acid (bpda) and 2 in a 1:1 mixture of dimethylacetamide (DMA) and xylenes in a sealed vial led to the formation of [ $\mathrm{Zn}_{2}$ (bpda) 2(solv.) ${ }_{\mathrm{n}}$ ] (13) as a red crystalline product. This material was also characterised by single crystal X-ray diffraction, revealing a twofold interpenetrated pillar layer structure, in which the metalloligand 2 bridges Zn(bpda) layers. Despite the considerable steric bulk of the clathrochelate complex, 13 possesses a solvent accessible void volume of $49 \%$ as determined by PLATON. ${ }^{[8]}$ The structure is also heavily distorted from ideal geometry, alluding to a potential structure-directing influence of the clathrochelate complex itself.

Having established the credentials of 


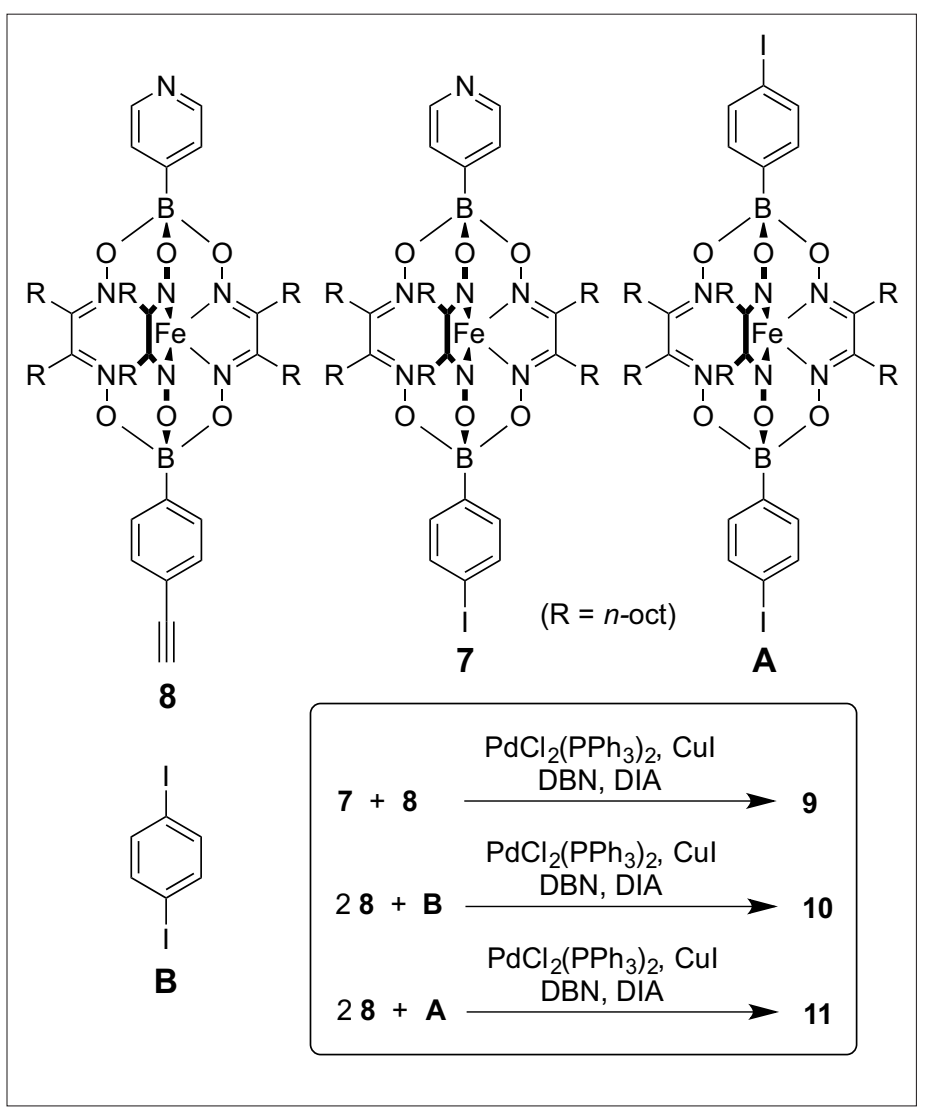

Scheme 3. Synthesis of $9-11$ by a Sonogashira coupling homologation approach. Adapted from ref. [5a] with permission from the Royal Society of Chemistry. 4,4'-bipyridyl metalloligands based upon clathrochelate complexes as building blocks in coordination-driven self-assembly, we turned our attention to the analogous 3,3'-bipyridyl complexes $\mathbf{3}$ and $\mathbf{4}$. 3,3'-Bipyridyl ligands comprised of two 3-pyridyl rings bridged by a linker group possess variable coordination vectors and are, consequently, inherently unpredictable building blocks. ${ }^{[5 b]}$ Rotation about the pyridine-linker bond enables an infinite number of conformations to be obtained and, hence, these ligands typically lead to the self-assembly of smaller, entropically favoured supramolecular structures in the presence of a suitable metal ion, rather than expanded architectures. ${ }^{[5 b]}$ However, we envisaged that the steric bulk of the clathrochelate complex cores of $\mathbf{3}$ and $\mathbf{4}$ would prevent the formation of small assemblies and encourage the formation of expanded arrays instead. Inspired by earlier results obtained by Fujita and coworkers, in which $\mathrm{Pd}_{3} \mathrm{~L}_{6}{ }^{6+}$ double-walled triangles and $\operatorname{Pd}_{4} \mathrm{~L}_{8}{ }^{8+}$ tetrahedra were formed by combining 'traditional' ligands 1,4-di(pyridin-3-yl)benzene or 4,4'-di(pyridin-3-yl)-1,1'-biphenyl with a naked $\mathrm{Pd}^{2+}$ ion, ${ }^{[9]}$ we added a $\mathrm{Pd}^{2+}$ salt to a solution of either $\mathbf{3}$ or $\mathbf{4}$ in acetonitrile and observed the formation of a single, highly symmetric species by NMR spectroscopy in both cases. Subsequent MS and crystallographic analysis revealed the formation of $\mathrm{Pd}_{6} \mathrm{~L}_{12}{ }^{12+}$ (where $\mathrm{L}=\mathbf{3}$ or $\mathbf{4}$ ) octahedral cage assemblies. The self-assembly of the

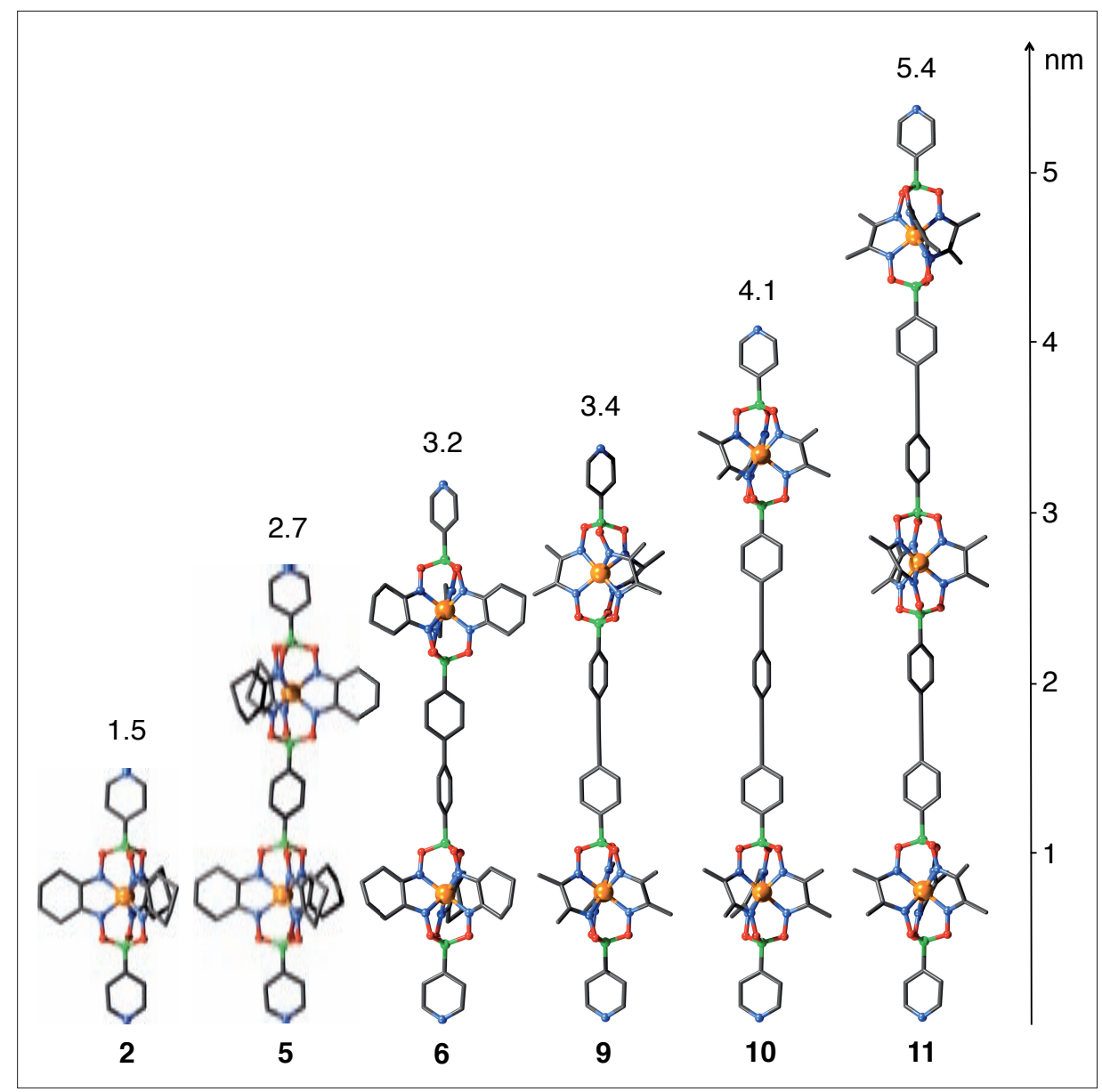

Fig. 1. Molecular structures of clathrochelate-based bipyridyl ligands as determined by X-ray crystallography $(2,5)$ and molecular modeling (6 and 9-11). The $n$-octyl side chains of 9-11 are substituted by methyl groups. Colour coding: C: grey, B: green, Fe: orange, N: blue, O: red. Adapted from ref. [5a] with permission from the Royal Society of Chemistry.
$\mathrm{Pd}_{6} \mathrm{~L}_{12}{ }^{12+}$ architecture is completely selective and no secondary species or side products were observed to form.

The geometrically variable nature of $3,3^{\prime}$-bipyridyl ligands is illustrated in the crystal structure of $\mathrm{Pd}_{6} \mathbf{3}_{12}{ }^{12+}$ shown in Fig. 3 . Due to the inversion symmetry about the centre point of the cage, there are six pairs of identical clathrochelate metalloligands comprising the structure. The angles between the planes of the pyridine rings within these individual building blocks are $9.3^{\circ}$, $13.7^{\circ}, 20.6^{\circ}, 66.8^{\circ}, 89.2^{\circ}$ and $90.0^{\circ}$, despite the fact that the geometry of the octahedral array formed by the $\mathrm{Pd}^{2+}$ ions is close to regular. The six different conformations observed in $\operatorname{Pd}_{6} 3_{12}{ }^{12+}$ are adopted in order to achieve the lowest energy conformation within the crystal, yet solution-phase NMR measurements show only one set of clathrochelate pyridine ring and oxime substituent protons, suggesting that conformational change is fast on the NMR timescale. Furthermore, in contrast to the assemblies reported by Fujita, the $\mathrm{Pd}_{6} \mathrm{~L}_{12}{ }^{12+}$ structure contains no trench-like $\mathrm{PdL} 2 \mathrm{Pd}$ macrocyclic motifs, in which two 3,3'-bipyridyl ligands bridge the same two $\mathrm{Pd}^{2+}$ ions. We propose that this is due to the steric bulk of 


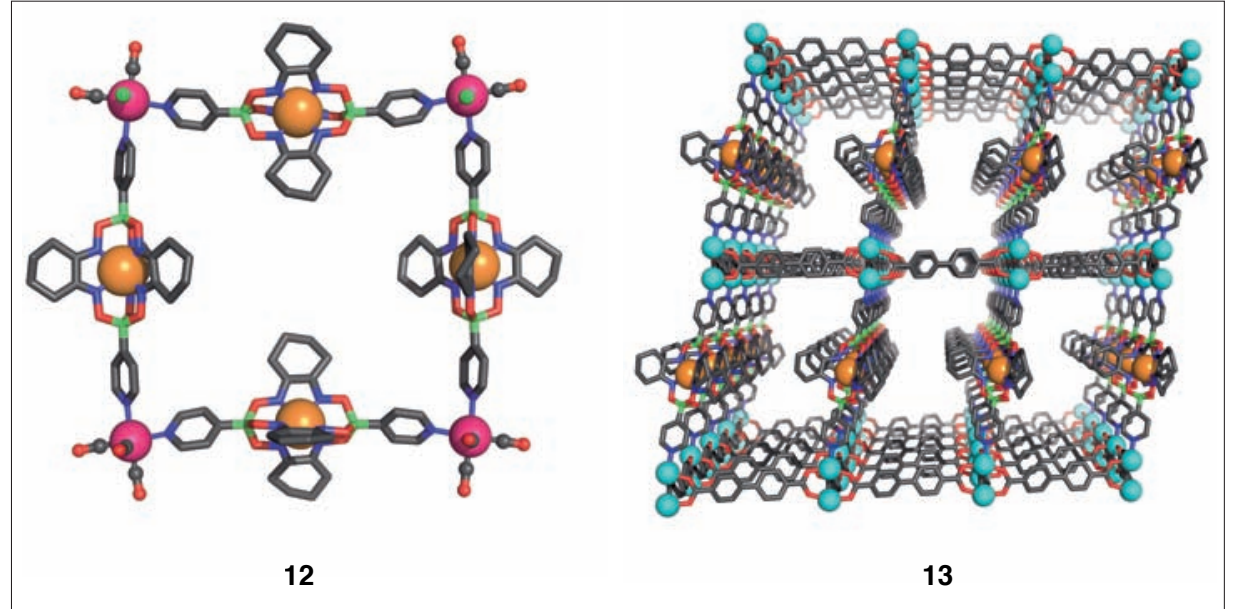

Fig. 2. Molecular structure of 12 (left) and $\mathbf{1 3}$ (right) in the crystal. C: grey, B: green, Fe: orange, N: blue, O: red, Re: magenta, Zn: cyan. Only one of the two interpenetrating networks of 13 is shown and hydrogen atoms have been omitted for clarity.

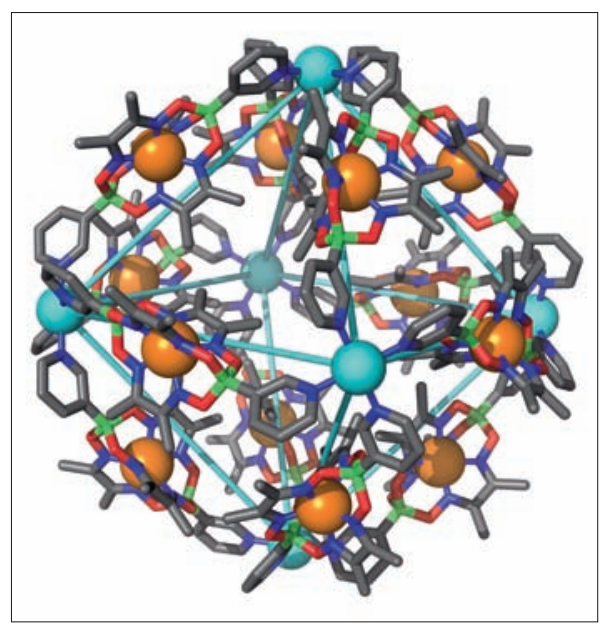

Fig. 3. The X-ray crystal structure of $\left(\mathrm{Pd}_{6} \mathbf{3}_{12}\right)$ $\left(\mathrm{NO}_{3}\right)_{12}$. C: grey, B: green, Fe: orange, $\mathrm{N}$ : blue, $\mathrm{O}$ : red, Pd: cyan. Hydrogen atoms and anions omitted for clarity.

the clathrochelate complex preventing two ligands from being in the close proximity necessary to form a $\mathrm{PdL}_{2} \mathrm{Pd}$ macrocycle. The structure-directing steric properties of clathrochelate-based metalloligands were alluded to in the structure of the coordination polymer $\mathbf{1 3}$ but, in the case of the assembly of $\mathrm{Pd}_{6} \mathrm{~L}_{12}{ }^{12+}$ octahedral cages, the sheer size of the clathrochelate complex is better described as structure-determining, as it enables an entirely new structure to be formed. Despite the fact that Fujita's work entailed the application of building blocks with the same geometry as $\mathbf{3}$ and $\mathbf{4}$, the outcome of the self-assembly process was completely different, because of the vast differences in steric bulk.

The $\mathrm{Pd}_{6} \mathbf{3}_{12}{ }^{12+}$ cage possesses a large internal cavity and, consequently, experiments were undertaken to investigate the guest encapsulation properties of this assembly. Given the overall $12+$ charge of the complex, along with the $\mathrm{CH}_{3}$ groups lining the interior of the structure, it was expected that hydrophobic anions would be good candidates for guest uptake. The $\mathrm{BF}_{4}^{-}$anion was observed to bind by ${ }^{19} \mathrm{~F}$ NMR, and the rate of exchange between bound and unbound $\mathrm{BF}_{4}^{-}$was found to be fast on the NMR timescale at room temperature in the case of $\operatorname{Pd}_{6} 3_{12}{ }^{12+}$, but slow in the case of $\operatorname{Pd}_{6} \mathbf{4}_{12}{ }^{12+}$, presumably since the larger cyclohexyl groups of $\mathbf{4}$ block, to some extent, the facial apertures of the cage. The difference in activation free energy of the $\mathrm{BF}_{4}^{-}$anion exchange process between cages $\operatorname{Pd}_{6} 3_{12}{ }^{12+}$ and $\operatorname{Pd}_{6} 4_{12}{ }^{12+}$ was calculated to be approximately $16 \mathrm{kJmol}^{-1}$. This result illustrates a relationship between the size of the oxime substituents of the clathrochelate complex and the functional characteristics of the cage. The much larger $\mathrm{BPh}_{4}^{-}$anion was also found to associate with $\operatorname{Pd}_{6} 3_{12}{ }^{12+}$ and the binding constant calculated to be $K_{a}=2.4( \pm 0.3)$ X $10^{3} \mathrm{M}^{-1}$ in $\mathrm{CD}_{3} \mathrm{CN}$ by ${ }^{1} \mathrm{H}^{a} \mathrm{NMR}$ experiments. The rate of $\mathrm{BPh}_{4}^{-}$binding is slow on the NMR timescale at room temperature. In the more polar solvent mixture of 2:1 $\mathrm{CD}_{3} \mathrm{CN}: \mathrm{D}_{2} \mathrm{O}$, the association constant is greater than $10^{5} \mathrm{M}^{-1}$, whilst in the significantly less polar solvent mixture of $1: 1$ $\mathrm{CDCl}_{3}: \mathrm{CD}_{3} \mathrm{CN}$, the association constant is too small to calculate reliably. The strong influence that solvent polarity has over the binding of $\mathrm{BPh}_{4}^{-}$by $\mathrm{Pd}_{6} 3_{12}{ }^{12+}$ suggests that solvation (hydrophobic) effects play a significant role in the free energy of association. Encapsulation of $\mathrm{BPh}_{4}^{-}$was unambiguously confirmed by single crystal X-ray crystallography, and Fig. 4 shows part of the structure of the mixed salt $\left[\mathrm{BPh}_{4} @\right.$ $\left.\mathrm{Pd}_{6} \mathbf{3}_{12}\right]\left[\mathrm{BF}_{4}\right]_{\mathrm{m}}\left[\mathrm{BPh}_{4}\right]_{\mathrm{n}}$, where $\mathrm{m}+\mathrm{n}=11$, clearly depicting the position of a single $\mathrm{BPh}_{4}^{-}$anion within the cavity of $\mathrm{Pd}_{6} 3_{12}{ }^{12+}$

In conclusion, we have prepared Fe(II) tris(dioxime) clathrochelate complexes functionalised with 3- and 4-pyridyl groups, and subsequently demonstrated their applications as metalloligands in the coordination-driven self-assembly of supramolecular structures. Building blocks up to $5.4 \mathrm{~nm}$ in length bearing 4-pyridyl capping groups have been synthesised from simple starting materials in one or two steps, and incorporated into a representative 2D molecular square and 3D coordination polymer. Furthermore, octahedral cage complexes with an unprecedented structure were prepared from clathrochelate complexes capped with 3 -pyridyl groups in combination with $\mathrm{Pd}^{2+}$ ions. In this case, not only was the clathrochelate complex itself shown to determine the outcome of the self-assembly process and enable a new structure to be formed, but the substituents of the oxime ligands were found to strongly influence the rate at which a cage was able to bind

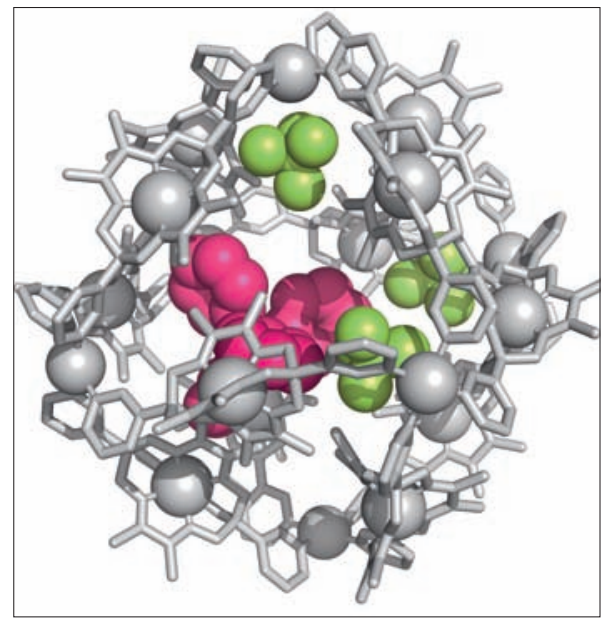

Fig. 4. Part of the $\mathrm{X}$-ray crystal structure of $\left[\mathrm{BPh}_{4} @ \mathrm{Pd}_{6} \mathbf{3}_{12}\right]\left[\mathrm{BF}_{4}\right]_{m}\left[\mathrm{BPh}_{4}\right]_{n}$, highlighting the encapsulated $\mathrm{BF}_{4}{ }^{-}$(yellow-green) and $\mathrm{BPh}_{4}$ (magenta) anions. External anions, hydrogen atoms and solvent molecules are omitted for clarity. Reproduced from ref. [5b], Royal Society of Chemistry.

and release an anionic guest. The results presented herein demonstrate that clathrochelate-based 3,3'- and 4,4'-bipyridyl metalloligands are highly promising building blocks for the preparation of functional supramolecular architectures. Work is ongoing in our laboratory to continue to explore and exploit the novel self-assembly behaviour of these complexes, whilst preparing clathrochelates bearing other functional groups appropriate for self-assembly applications. ${ }^{[10]}$

\section{Acknowledgement}

The research leading to these results has received funding from the People Programme (Marie Curie Actions) of the European Union's Seventh Framework Programme FP7/20072013/under REA grant agreement no 264645.

Received: January 27, 2015 
[1] Selected recent reviews: a) B. H. Northrop, D. Chercka, P. J. Stang, Tetrahedron 2008 , 64, 11495; b) R. W. Saalfrank, H. Maid, A. Scheurer, Angew. Chem., Int. Ed. 2008, 47, 8794; c) R. Chakrabarty, P. S. Mukherjee, P. J. Stang, Chem. Rev. 2011, 111, 6810; d) T R. Cook, Y.-R. Zheng, P. J. Stang, Chem. Rev. 2012, 113, 734; e) L. Song, J. Zhang, L. Sun, F. Xu, F. Li, H. Zhang, X. Si, C. Jiao, Z. Li, S. Liu, Y. Liu, H. Zhou, D. Sun, Y. Du, Z. Cao, Z. Gabelica, Energy \& Environ. Sci. 2012, 5, 7508; f) P. Thanasekaran, T.-T. Luo, J.-Y. Wu, K.-L. Lu, Dalton Trans. 2012, 41, 5437; g) H. Furukawa, K. E. Cordova, M. O'Keeffe, O. M. Yaghi, Science, 2013, 341, 1230444; h) L. F. Lindoy, K.-M. Park, S. S. Lee, Chem. Soc. Rev. 2013, 42, 1713; i) T. K. Ronson, S. Zarra, S. P. Black, J. R. Nitschke, Chem. Commun. 2013, 49, 2476; j) M. D. Ward, P. R. Raithby, Chem. Soc. Rev. 2013, 42, 1619; k) W. Lu, Z. Wei, Z.Y. Gu, T.-F. Liu, J. Park, J. Park, J. Tian, M. Zhang, Q. Zhang, T. Gentle III, M. Bosch, H.C. Zhou, Chem. Soc. Rev. 2014, 16, 5561; 1) S. Mukherjee, P. S. Mukherjee, Chem. Commun. 2014, 50, 2239.

[2] a) N. Stock, S. Biswas, Chem. Rev. 2011, 112 , 933; b) N. N. Adarsh, P. Dastidar, Chem. Soc. Rev. 2012, 41, 3039; c) M. Du, C.-P. Li, C.S. Liu, S.-M. Fang, Coord. Chem. Rev. 2013, 257, 1282; d) N. J. Young, B. P. Hay, Chem. Commun. 2013, 49, 1354; e) Y.-F. Han, G.-X. Jin, Acc. Chem. Res. 2014, 47, 3571.

[3] Y. Z. Voloshin, N. A. Kostromina, R. Kramer, 'Clathrochelates: Synthesis, Structure and Properties', Elsevier, Amsterdam, 2002.
[4] Selected examples: a) Y. Z. Voloshin, O. A. Varzatskii, I. I. Vorontsov, M. Y. Antipin, Angew. Chem., Int. Ed. 2005, 44, 3400; b) O. Pantani, S. Naskar, R. Guillot, P. Millet, E. AnxolabehereMallart, A. Aukauloo, Angew. Chem., Int. Ed. 2008, 47, 9948; c) W. J. Liu, W. J. Huang, M. Pink, D. Lee, J. Am. Chem. Soc. 2010, 132, 11844; d) Y. Z. Voloshin, A. V. Dolganov, O. A. Varzatskii, Y. N. Bubnov, Chem. Commun. 2011, 47, 7737; e) E. Anxolabéhère-Mallart, C. Costentin, M. Fournier, S. Nowak, M. Robert, J.-M. Savéant, J. Am. Chem. Soc. 2012, 134, 6104; f) I. L. Odinets, O. I. Artyushin, E. V. Matveeva, A. V. Vologzhanina, Y. Z. Voloshin, Phosphorus, Sulfur, and Silicon and the Related Elements, 2012, 188, 159; g) Y. Z. Voloshin, A. S. Belov, O. A. Varzatskii, S. V. Shul'ga, P. A. Stuzhin, Z. A. Starikova, E. G. Lebed, Y. N. Bubnov, Dalton Trans. 2012, 41, 921; h) Y. Z Voloshin, O. A. Varzatskii, S. V. Shul'ga, I. N. Denisenko, A. V. Vologzhanina, Y. N. Bubnov, Inorg. Chem. Commun. 2012, 17, 128; i) V. V. Novikov, O. A. Varzatskii, V. V. Negrutska, Y N. Bubnov, L. G. Palchykovska, I. Y. Dubey, Y. Z. Voloshin, J. Inorg. Biochem. 2013 , 124,$42 ;$ j) S. E. Solovieva, A. A. Tyuftin, A. A. Muravev, M. Gruner, W. Habicher, S. V. Korobko, I. S. Antipin, A. I. Konovalov, Y. N. Bubnov, Y. Z. Voloshin, Polyhedron, 2013, 50, 90; k) O. A. Varzatskii, I. N. Denisenko, S. V. Volkov, A. S. Belov, A. V. Dolganov, A. V. Vologzhanina, V. V. Novikov, Y. N. Bubnov, Y. Z. Voloshin, Eur. J. Inorg. Chem. 2013, 3178; 1) A. B. Burdukov, M. A. Vershinin, N. V. Pervukhina, E. G. Boguslvaskii, I. V. Eltsov, L. A. Shundrin, S. L. Selector, A. V. Shokurov, Y
Z. Voloshin, Inorg. Chem. Commun. 2014, 44, $183 ;$ m) V. B. Kovalska, M. Y. Losytskyy, O. A. Varzatskii, V. V. Cherepanov, Y. Z. Voloshin, A. A. Mokhir, S. M. Yarmoluk, S. V. Volkov, Bioorg. \& Med. Chem. 2014, 22, 1883; n) O. A. Varzatskii, V. V. Novikov, S. V. Shulga, A. S. Belov, A. V. Vologzhanina, V. V. Negrutska, I. Y. Dubey, Y. N. Bubnov, Y. Z. Voloshin, Chem. Commun. 2014, 50, 3166; o) O. A. Varzatskii, S. V. Shul'ga, A. S. Belov, V. V. Novikov, A. V. Dolganov, A. V. Vologzhanina, Y. Z. Voloshin, Dalton Trans. 2014, 48, 17934 .

[5] a) M. D. Wise, A. Ruggi, M. Pascu, R. Scopelliti, K. Severin, Chem. Sci. 2013, 4, 1658; b) M. D. Wise, J. J. Holstein, P. Pattison, C. Besnard, E. Solari, R. Scopelliti, G. Bricogne, K. Severin, Chem. Sci. 2015, 6, 1004.

[6] R. Chinchilla, C. Najera, Chem. Soc. Rev. 2011, 40, 5084.

[7] H. Deng, S. Grunder, K. E. Cordova, C. Valente, H. Furukawa, M. Hmadeh, F. Gándara, A. C. Whalley, Z. Liu, S. Asahina, H. Kazumori, M. O'Keeffe, O. Terasaki, J. F. Stoddart, O. M. Yaghi, Science 2012, 336, 1018.

[8] A. Spek, Acta Crystallogr., Sect. D: Biol. Crystallogr. 2009, 65, 148.

[9] D. K. Chand, K. Biradha, M. Kawano, S. Sakamoto, K. Yamaguchi, M. Fujita, Chem.Asian J. 2006, 1, 82 .

[10] M. Pascu, M. Marmier, C. Schouwey, R. Scopelliti, J. J. Holstein, G. Bricogne, K. Severin, Chem.-Eur. J. 2014, 20, 5592. 